\title{
A Consortium for Ocean Circulation and Climate Estimation
}

\author{
John Marshall \\ Department of Earth, Atmospheric, and Planetary Sciences, Room 54-1526 \\ Massachusetts Institute of Technology, 77 Massachusetts Ave., Cambridge, MA 02139 \\ Phone: (617) 253-9615 fax: (617) 253-4464 email: marshall@ gulf.mit.edu \\ Carl Wunsch \\ Department of Earth, Atmospheric, and Planetary Sciences, Room 54-1520 \\ Massachusetts Institute of Technology, 77 Massachusetts Ave., Cambridge, MA 02139 \\ Phone: (617) 253-5937 fax: (617) 253-4464 email: cwunsch@ pond.mit.edu \\ Award Number: N000149911050 \\ HTML link: http://ecco-group.org/ \\ other sites closely linked to the project: http://mitgcm.lcs.mit.edu/ \\ http://ecco.jpl.nasa.gov/odap/ and http://ecco.ucsd.edu/
}

\section{LONG-TERM GOALS}

To bring ocean state estimation from its present experimental stage on to an operational footing in which global ocean circulation models are routinely constrained by remotely sensed and in-situ data to yield the evolving three-dimensional state of the ocean.

\section{OBJECTIVES}

To develop and apply ocean circulation models and state estimation techniques in support of global ocean state estimation.

\section{APPROACH}

The approach we are taking is to:

(i) develop the MIT ocean circulation model in support of state estimation applications-improved algorithms and physical paramerizations of the forward model and maintenance and scientific application of its tangent linear and adjoint counterparts (J. Marshall and Carl Wunsch together with research scientists A. Adcroft, C. Hill and P. Heimbach, programmer D. Jamous, and student).

(ii) explore different estimation methods, including robust control approaches (C. Wunsch and postdoc M. Losch).

(iii) analyze and scientifically explore the ECCO state estimates (postdoc J. Scott). 


\section{Report Documentation Page}

Form Approved

OMB No. 0704-0188

Public reporting burden for the collection of information is estimated to average 1 hour per response, including the time for reviewing instructions, searching existing data sources, gathering and maintaining the data needed, and completing and reviewing the collection of information. Send comments regarding this burden estimate or any other aspect of this collection of information,

including suggestions for reducing this burden, to Washington Headquarters Services, Directorate for Information Operations and Reports, 1215 Jefferson Davis Highway, Suite 1204, Arlington

VA 22202-4302. Respondents should be aware that notwithstanding any other provision of law, no person shall be subject to a penalty for failing to comply with a collection of information if it

does not display a currently valid OMB control number.

1. REPORT DATE

30 SEP 2002

2. REPORT TYPE

3. DATES COVERED

00-00-2002 to 00-00-2002

4. TITLE AND SUBTITLE

A Consortium for Ocean Circulation and Climate Estimation

6. AUTHOR(S)

5. CONTRACT NUMBER

5b. GRANT NUMBER

5c. PROGRAM ELEMENT NUMBER

5d. PROJECT NUMBER

5e. TASK NUMBER

5f. WORK UNIT NUMBER

7. PERFORMING ORGANIZATION NAME(S) AND ADDRESS(ES)

8. PERFORMING ORGANIZATION

REPORT NUMBER

Department of Earth, Atmospheric, and Planetary Sciences,,Room

54-1526,Massachusetts Institute of Technology,,77 Massachusetts

Ave.,Cambridge,,MA,02139

9. SPONSORING/MONITORING AGENCY NAME(S) AND ADDRESS(ES)

10. SPONSOR/MONITOR'S ACRONYM(S)

11. SPONSOR/MONITOR'S REPORT

NUMBER(S)

12. DISTRIBUTION/AVAILABILITY STATEMENT

Approved for public release; distribution unlimited

13. SUPPLEMENTARY NOTES

14. ABSTRACT

To bring ocean state estimation from its present experimental stage on to an operational footing in which global ocean circulation models are routinely constrained by remotely sensed and in-situ data to yield the evolving three-dimensional state of the ocean.

15. SUBJECT TERMS

16. SECURITY CLASSIFICATION OF

a. REPORT

unclassified b. ABSTRACT unclassified c. THIS PAGE unclassified
17. LIMITATION OF ABSTRACT

Same as

Report (SAR)
18. NUMBER OF PAGES

5 19a. NAME OF

RESPONSIBLE PERSON 


\section{WORK COMPLETED}

The MITgcm that is at the heart of the ECCO data assimilation system has undergone continued improvement (Adcroft, Hill, and Marshall). The model has been documented and release 1 will be made public at the end of September 2001—see http://mitgcm.lcs.mit.edu/.

In Stammer et al., 2001a,b we completed first overall discussions of ECCO results including tests of estimates against withheld data. State estimates have been used to calculate global flux divergences (with S. Josey and W. Large) and energetics of the ocean circulation studied (with J. Scott). We have started exploring the use of robust control methods as a future alternative method. One student (G. Gebbie) set up an eddy resolving version of the model in the subduction experiment region to understand eddy-resolving data assimilation. Another student (X. Li), using the offline code, began constraining the model with tritium and fluorocarbon data.

We have also been involved in 'outreach'-C. Wunsch co-directed the WOCE Young Investigator's Workshop at NCAR.

\section{RESULTS}

In collaboration with Scripps and JPL, the ECCO assimilation system has been used to demonstrate that global ocean models can be meaningfully constrained by global observations to yield an estimate of the evolving state of the ocean (see figure 1). Moreover, we have shown that the resulting state estimates are better than that which would be obtained by using either observations or models alone. These are described in two submitted papers-Stammer et al. (2001 a,b).

Four manuscripts on ECCO state estimates and their scientific interpretation were completed or nearly so. We showed a clear importance of high energy, high latitude barotropic motions to sampling and modeling the ocean.

Our future goal is to continue to improve our models and assimilation schemes and make global state estimates at higher, and eventually, eddy-resolving resolutions.

\section{IMPACT/APPLICATIONS}

The impact of the ECCO project is potentially huge because it is pioneering a new way of doing oceanography. We are demonstrating that global ocean models can be meaningfully constrained by global observations to yield an estimate of the state that is better then either model or observations alone. We believe that the methods being explored in ECCO will become widely used in oceanography and change the way we observe and model the ocean.

\section{TRANSITIONS}

An important part of the ECCO project is the continued development of the MITgcm to yield a widely available and used community model. MITgcm is now being used in global, regional, coastal and process study applications by a growing group of scientists. The MIT development group already has strong collaborations with JPL, Scripps, WHOI, MIT, UConn and Johns Hopkins. The public release of the model scheduled for September 2001 will make the model and its adjoint available to all. The ECCO ocean state estimates are also publically available and can be used by all. 


\section{RELATED PROJECTS}

ECCO is a close collaboration between Scripps (Professor Detlef Stammer) (http://ecco.ucsd.edu/), JPL (Drs. Lee Fu and Ichiro Fukumori) (http://ecco.jpl.nasa.gov/odap) and MIT.

The FRONTS project, led by Professor Jim O'Donnell and Dr Chris Edwards (http://nopp.uconn.edu/), also makes use of the models and techniques developed here.

\section{PUBLICATIONS}

The following publications made direct use of the models developed and run with ECCO support.

Bugnion, V. and C. Hill (2001a) The climatological sensitivity of thermohaline overturning strength, an adjoint study. Part I-The idealized behavior of decadal to centennial thermohaline sensitivity, submitted to Journal of Climate.

Bugnion, V. and C. Hill (2001b) The climatological sensitivity of thermohaline overturning strength, an adjoint study. Part II-Thermohaline overturning sensitivity in the contemporary climate, submitted to Journal of Climate

Dutay, J.-C., J. Bullister, S. Doney, J. Orr, R. Najjar, K. Caldeira, J.-M. Champin, H. Drange, M. Follows, Y. Gao, N. Gruber, D. Hecht, A. Ishida, F. Joos, K. Lindsay, Madec, E. Maier-Reimer, J. Marshall, R. Matear, P. Monfray, Plattner, J. Sarmiento, R. Schlitzer, R. Slater, I. Totterdell, M.F. Weirig, Y. Yamanaka, , and A. Yool (2001) Evaluation of ocean model ventilation with CFC-11: Comparison of 13 global ocean models, to appear in Ocean Modeling.

Marshall, J., J. Nilsson, and D. Jamous (2001) Entry, flux and exit of potential vorticity in ocean circulation. J. Phys. Oceangr., vol. 31, no.3, 777-789

McKinley, G., M.J. Follows, and J.C. Marshall (2000) Interannual variability of oxygen fluxes in the North Atlantic. Geophys. Res. Lett., 27, 2933-2936.

Stammer, D., C. Wunsch, R. Giering, C. Eckert, P. Heimbach, J. Marotzke, A. Adcroft, C.N. Hill, and J. Marshall (2001a) Volume, heat and freshwater transports of the Global Ocean Circulation 19921997, estimated from a general circulation model constrained by WOCE data, submitted to J. Geophy. Res.

Stammer, D., C. Wunsch, R. Giering, C. Eckert, P. Heimbach, J. Marotzke, A. Adcroft, C.N. Hill, and J. Marshall (2001b) The global ocean circulation during 1992-1997, estimated from ocean observations and a general circulation model, submitted to J. Geophy. Res.

Wunsch, C. (2001) Oceanic age and transient tracers. Analytical and numerical solutions, submitted to J. Geophy. Res. 
a

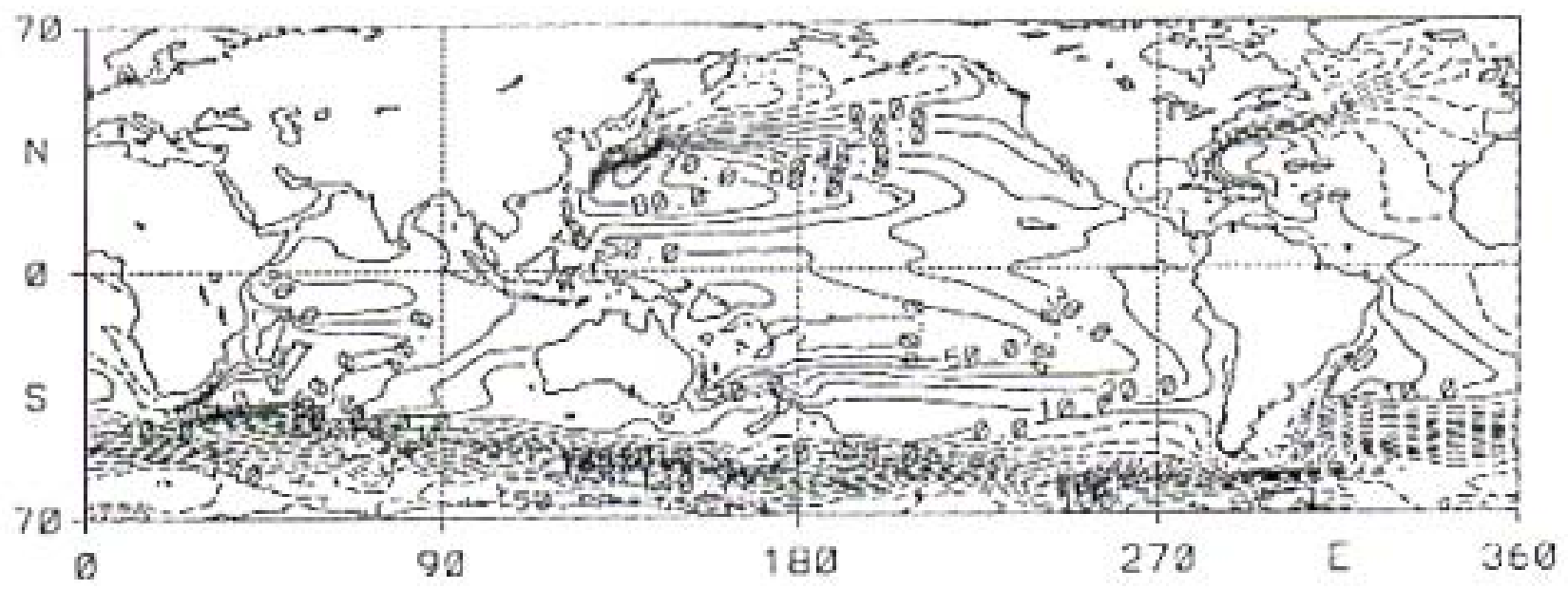

b

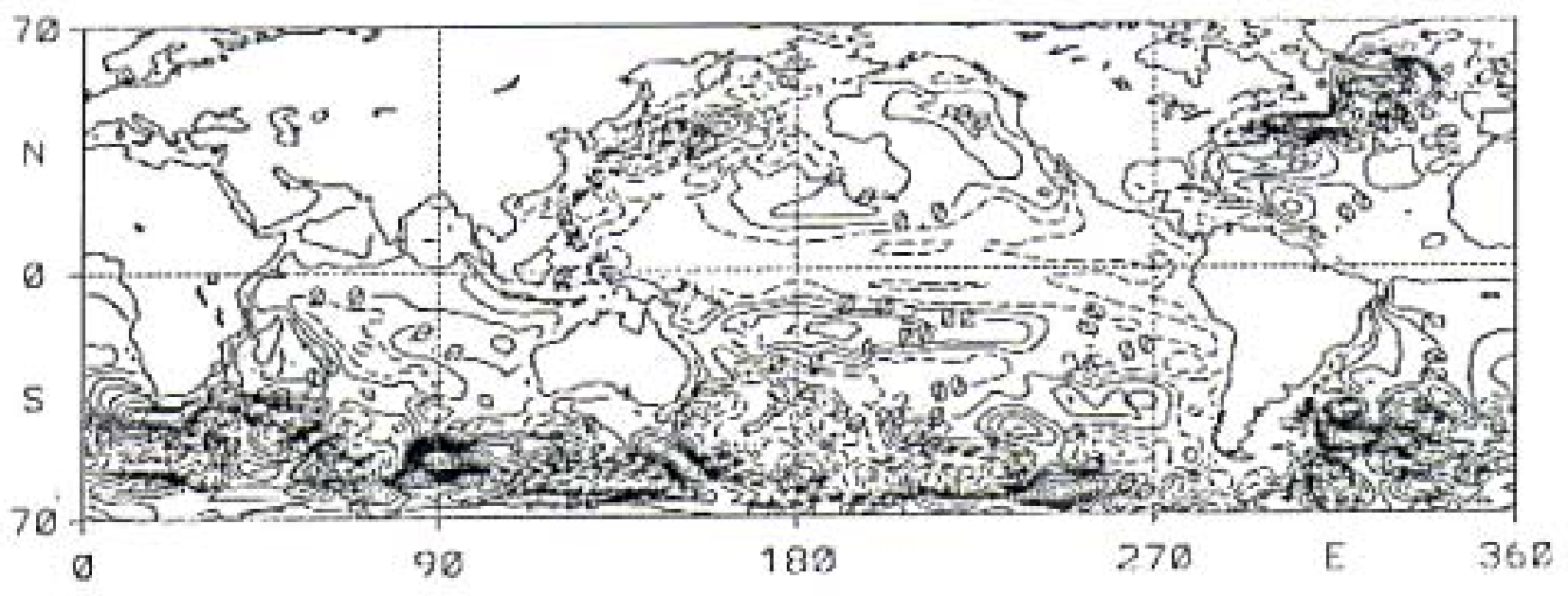

Figure 1. (a) The time mean estimated surface elevation from the one-year period 1993. Contour interval is 10 centimeters. (b) Difference in the mean elevation fields from the optimum solution minus the model first guess. Contour interval is $2 \mathrm{~cm}$. 